\title{
BMJ Open Exploring the health and service utilisation of general practice patients with a history of adverse childhood experiences (ACEs): an observational study using electronic health records
}

\author{
Katie Hardcastle (D) , ${ }^{1}$ Mark A Bellis, ${ }^{1,2}$ Catherine A Sharp, ${ }^{2}$ Karen Hughes ${ }^{1,2}$
}

To cite: Hardcastle $\mathrm{K}$, Bellis MA, Sharp CA, et al. Exploring the health and service utilisation of general practice patients with a history of adverse childhood experiences (ACEs): an observational study using electronic health records. BMJ Open 2020;10:e036239. doi:10.1136/ bmjopen-2019-036239

- Prepublication history for this paper is available online. To view these files, please visit the journal online (http://dx.doi. org/10.1136/bmjopen-2019036239).

Received 06 December 2019 Revised 20 July 2020 Accepted 07 August 2020
A) Check for updates

(C) Author(s) (or their employer(s)) 2020. Re-use permitted under CC BY-NC. No commercial re-use. See rights and permissions. Published by BMJ.

${ }^{1}$ WHO Collaborating Centre on Investment for Health and Well-being, Public Health Wales, Wrexham, UK

${ }^{2}$ Public Health Collaborating Unit, BIHMR, College of Human Sciences, Bangor University, Bangor, UK

Correspondence to

Katie Hardcastle;

katie.hardcastle@wales.nhs.uk

\section{ABSTRACT}

Objectives To examine the relationships between adverse childhood experiences (ACEs), chronic health and health service utilisation among a sample of general practice patients.

Design Cross-sectional observational study using anonymised data from electronic health records for 763 patients.

Setting Four general practices in northwest England and North Wales.

Outcome measures Patient demographic data (age, gender); body mass index; self-reported smoking status; self-reported ACEs; diagnosis of chronic health conditions; current mental health problems; total number of service contacts and repeat medication use in the previous 6 months.

Results A history of ACEs (experiencing abuse or neglect as a child, and/or growing up in a household characterised by violence, substance use, mental health problems or criminal behaviour) was strongly independently associated with current mental health problems, smoking and chronic obstructive pulmonary disease, showing a dose-response relationship with level of ACE exposure. Medication use and contact were significantly greater among patients with high ACE exposure ( $\geq 4 \mathrm{ACES}$ ), compared with those with no ACEs. However, contrary to findings from population studies, health service utilisation was not significantly different for patients with increased ACE exposure (1-3 ACEs) and their ACE-free counterparts.

Conclusions Findings highlight the contribution ACEs make to unequal distributions of risk to health and wellbeing and patterns of health service use in the UK.

\section{INTRODUCTION}

Across the globe, ageing and growing populations and the increasing prevalence of chronic diseases continue to exert pressures on primary healthcare. ${ }^{1}$ Evolving challenges of demand, resource, complexity and expectation are particularly pronounced in systems of universal state-supported care, such as Spain $^{23}$ and the UK. ${ }^{4}$ Increasingly there are calls for innovations to support more
Strengths and limitations of this study

- This study uniquely analyses data on adverse childhood experiences (ACEs) that is contained within primary care electronic health records.

- Rather than relying on patient self-reported outcomes, analyses are based on objective measures of health (diagnosis) and service utilisation.

- Due to the nascence of approaches to collecting ACE information in practice, this study is based on only a small sample derived from four different general practices.

- Available service use data considered only a relatively short time period, which could be subject to seasonal trends and other confounding effects.

appropriate access to care and improve the patient experience ${ }^{67}$ Patient surveys describe overall positive views of UK general practice. ${ }^{8}$ However, almost one in seven respondents to the 2019 GP Patient Survey who identified some form of mental health need felt that at their most recent appointment, the healthcare professional did not recognise or understand their mental health issues. ${ }^{8}$ Mental health places particular demands on general practice. Around $30 \%-40 \%$ of general practice presentations in the UK involve a mental illness component ${ }^{9} 10$ and figures suggest as many as $90 \%$ of adults with mental health problems are supported solely in primary care. $^{11}$

Over two decades of global research now demonstrates the profound impact of early life experiences on physical and especially mental health, both in the short-term ${ }^{12} 13$ and throughout the life course. ${ }^{14}$ In the absence of protective factors, adverse childhood experiences (ACEs) such as abuse, neglect, growing up with a caregiver who abuses alcohol or drugs, or exposure to other 
traumatic experiences, can promote a state of hyperarousal and a prolonged toxic stress response. ${ }^{15}$ This can impact the hormonal, immunological and neurobiological development of the growing child, ${ }^{15} 16$ shaping their behaviour and the way they build relationships and interact with the world. Toxic stress can result in systemic inflammation throughout the body and increases allostatic load. This biological embedding of adversity, along with health-harming behaviours that emerge often as coping mechanisms, places individuals at greater risk of chronic disease,${ }^{17}$ complex multi-morbidity ${ }^{18}$ and even early mortality. ${ }^{19}$ Throughout the life course, those with a history of ACEs are also considerably more likely to experience mental health issues such as anxiety and depression. ${ }^{20}{ }^{21}$ Some evidence suggests that as a result of these associations, adults with a history of childhood adversity make more frequent visits to their general practitioner (GP),${ }^{2223}$ are more likely to present with a range of somatic complaints $^{24}$ and rate their own overall health more negatively, ${ }^{25}$ thus placing large demands on services. Equally, other studies report that patients with ACEs are actually less likely to engage in preventative healthcare ${ }^{26}{ }^{27}$ show poorer adherence to treatment ${ }^{28}$ and struggle to build trusting relationships with health professionals. ${ }^{29}$ In one study from the USA, patients with high ACE exposure ( $\geq 4$ ACEs) made more but kept fewer GP appointments. ${ }^{18}$

There is a growing recognition among health practitioners of the impact of early life experiences on later health and the need for services to recognise and respond to historic or ongoing trauma. ${ }^{30}$ However, evidence suggests that childhood adversity is rarely the focus of primary care consultations. ${ }^{31}$ Practitioners may feel they lack the time or skills to enquire about ACEs or other trauma, or perceive there to be a lack of viable onward referral pathways for affected patients. ${ }^{32}{ }^{33}$ While different approaches to asking about ACEs in health settings are emerging, ${ }^{34}$ there remain questions about their scalability and impact. ${ }^{35}$ Asking about childhood adversity may alter support for those with complex multi-morbidity and mental health issues in general practice settings. ${ }^{36}$ Currently, however, little information is available on even the relationships between exposure to ACEs and GP health service utilisation. During the period April 2017 -April 2018, four practices in England and Wales independently trialled ACE enquiry as part of their routine practice. Using data available from electronic health records (EHR) in these practices, the objectives of this study were to determine the relationship between ACEs and chronic health conditions, and ACEs and health service utilisation among a sample of general practice patients.

\section{METHODS}

\section{Design and data extraction}

Secondary analysis was carried out on anonymised crosssectional data extracted from four general practices: a large multi-site general practice in Lancashire, northwest
England and three practices in Anglesey, North Wales. Practice sizes ranged from 6500 to 16000 patients. The study population was all patients for whom ACE data were available (see the Measures section). Analyses included all chronic health outcomes that practices were able to reliably extract. Practice or data managers extracted EHR data from clinical information systems. Data were imported into Microsoft Excel, de-identified (removing names, patient NHS numbers, addresses, and reducing age data to categories) and securely shared with KHa via email in password-protected files. Particular care was taken to ensure that no patient was identifiable by unique diagnosis. Data were extracted by practices for a total of 783 patients. Cases were excluded from analyses if patients did not answer three or more (out of ten) ACE questions or EHR data were inaccessible or incomplete (eg, for patients that were new to the practice and had no historic service use data for the previous 6 months or whose medical history (ie, Read codes for chronic health conditions) was unknown). This resulted in a final analytical sample of $n=763$.

\section{Patient and public involvement}

This analysis was conducted without patient involvement. Patients were not invited to comment on the study design and were not consulted to develop patientrelevant outcomes or interpret the results. Patients were not invited to contribute to the writing or editing of this document for readability or accuracy.

\section{Measures}

\section{Demographic data}

Data were provided on patient gender and age, split into three discrete age categories $(18-30 ; 31-50 ; \geq 51$ years). Ethnicity data were recorded by practices using 2011 UK census categories but were not included in analyses due to the high frequency of missing data $(>50 \%)$. Practices were unable to provide data on patient deprivation. However, different practice locations were included in multivariate analyses to control for potential area-level confounders.

\section{Adverse childhood experiences}

Practices involved in the study were those that used a simplified version of established ACE questions from the Centers for Disease Control and Prevention short ACE tool $^{37}$ to measure childhood exposure (before age 18 years) to 10 forms of abuse and family dysfunction (see online supplemental table 1). In these practices, patients were provided with written self-report ACE questionnaires, which they completed alone in the waiting area prior to their appointment. The total number of ACEs experienced was recorded in EHR. This was categorised into three levels of ACE exposure for analysis: none; increased exposure (1-3 ACEs) and high exposure ( $\geq 4$ ACEs); as is consistent with methodologies applied elsewhere. ${ }^{148}$ It is important to note that these categories are intended to illustrate potential differences in outcomes 
by level of ACE exposure. They do not represent thresholds for experiencing negative impacts of ACEs and have not been identified as having practical application for screening or intervention.

\section{Health data}

Read codes are a thesaurus of clinical terms that provide a standard vocabulary for clinicians to record patient findings and procedures in health and social care ${ }^{39}$ They are considered acceptable and valid for use in health research. ${ }^{40}$ Patients were considered diagnosed with the following physical health conditions if their EHR included an existing Read code for that condition: asthma; cancer (any); cardiovascular disease (CVD; including coronary heart disease, myocardial infarction, heart failure, angina, stroke and transient ischaemic attack); chronic obstructive pulmonary disease (COPD); type II diabetes and hypertension. Patients with Read codes for two or more of the above conditions were considered multimorbid; a proxy for more complex healthcare needs. Current mental health was also examined and included any diagnosed mental health problem. Due to the high frequency of low level mental health presentations within Read codes (eg, low mood, acute stress), patients were identified as having a current mental health problem only if they were Read coded for that condition and were currently on medication consistent with their diagnosis.

EHR lifestyle data on body mass index (BMI; measured by practices) and smoking status (self-reported by patients) were included in analyses if collected or updated by the practice within the last 5 years. Patients with a BMI $\geq 30 \mathrm{~kg} / \mathrm{m}^{2}$ were considered obese. Due to low frequency of ex-smokers, EHR categories of self-reported smoking status (current smoker, ex-smoker, non-smoker) were re-categorised to identify current smokers only (yes/no).

\section{Service use data}

EHR data were extracted on the number of GP appointments patients attended in the previous 6 months. This included face-to-face appointments with any clinician (all practices) and, where applicable, telephone triage appointments (Lancashire practice only), but did not include appointments that were booked but subsequently not attended. For comparability and due to large variations in general practice approaches and the frequency of contact found between practices, the mean number of contacts per practice was calculated and patients that attended or were telephone triaged more frequently than the mean for their practice were identified as 'high contact' patients (North Wales A $>4$ contacts in 6 months; North Wales B $>1$; North Wales C $>7$; Lancashire $>5$ ). Similarly, large between-practice variations resulted in a relative measure for medication use. Patients were identified as having 'high repeat prescription use' if they were in receipt of more unique scripts than the practice mean (North Wales A >3 scripts; North Wales B $>1$; North Wales $\mathrm{C}>5$; Lancashire $>3$ ). Contraceptives were excluded from medication totals.

\section{Statistical analysis}

Anonymous patient data were imported into SPSS V.24 for cleaning and statistical analyses. Analyses used $\chi^{2}$ tests and $\chi^{2}$ for trend tests for initial bivariate examination of the relationship between ACEs and: chronic health outcomes (asthma, cancer, COPD, CVD, type II diabetes, hypertension, mental health; table 1 and online supplemental table 2); lifestyle factors (obesity, smoking; table 1); service use outcomes (high contact and high repeat prescription use; table 2). Binary logistic regression was also used to examine the independent contributions of ACEs and demographics (age, gender, GP practice location) to these chronic health and service use outcomes (table 3 and online supplemental table 3). A generalised linear model (GLM) was used to generate adjusted means (ie, estimated marginal means) for service use outcomes for individuals with different levels of ACE exposure (figure 1). GLM allows covariate and categorical variables to be fitted to dependent variables and the resultant model can be used to generate estimates for the dependent variable for given values of the independent variable. ${ }^{41} \mathrm{P}$ values were not adjusted for having more than one health condition or service utilisation measure and significance was defined as $\mathrm{p}<0.05$.

\section{RESULTS}

Patients in the study population ranged in age from 18 to 93 years (mean age: 53.1 years) and $61.9 \%$ were women, reflecting the overall demographics of adult patients attending the practices. Overall prevalence of chronic health conditions identified in EHR ranged from 7.3\% recorded as having cancer (all forms) to $28.6 \%$ of patients with hypertension. Significant differences in the sampled population prevalence of many conditions were found between practices (table 1). Patients had a mean of 3.1 contacts in the previous 6 months $(\mathrm{SD}=4.3)$ and 3.9 items on current repeat prescription $(\mathrm{SD}=5.4)$.

\section{ACE exposure prevalence in the sampled patient population}

Just over half of patients (51.9\%) had been exposed to one or more ACE during the first 18 years of life (table 1 ). ACE exposure differed significantly by age, with patients aged 18-30 years reporting a higher prevalence of high ACE exposure (11.2\% high exposure; $31-50$ years $9.7 \%$; $\geq 51$ years $\left.7.7 \% ; \chi^{2}=17.489, \mathrm{p}<0.001\right)$. There was no significant difference in ACE prevalence by gender. When comparing across all four practices, a significantly greater proportion of patients from Lancashire reported high ACE exposure (15.0\% high exposure; North Wales A 5.0\%; North Wales B 7.8\%; North Wales C $6.4 \%$; $\left.\chi^{2}=71.398, \mathrm{p}<0.001\right)$.

\section{ACEs and mental health}

Across all age categories, a significant dose-response relationship was found between ACE exposure and current diagnosis and treatment for any mental health issue (table 1; online supplemental table 2). Female patients 


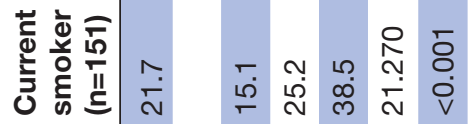

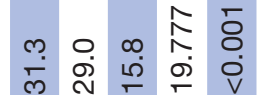

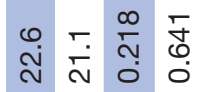

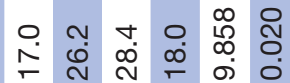

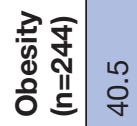

穴

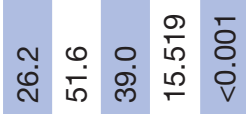

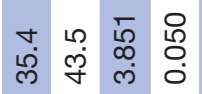

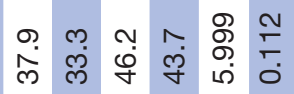

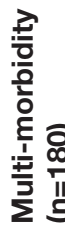

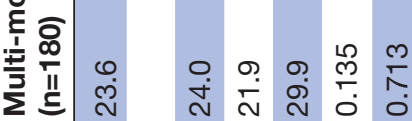

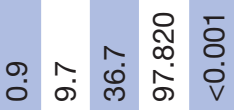

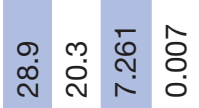

○. เ

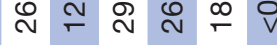

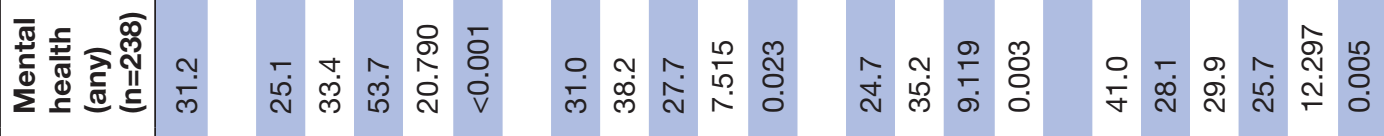

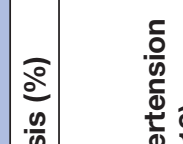

案

$\stackrel{\infty}{\stackrel{\infty}{N}} \stackrel{0}{\infty}$

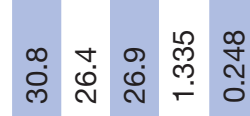

ஒே.

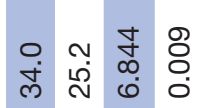

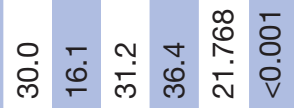

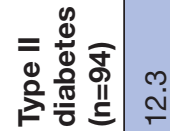

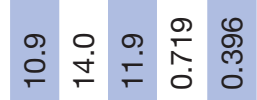

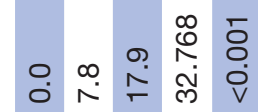

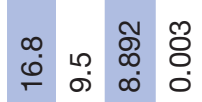

مٌ

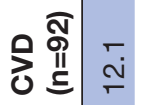

г্লে

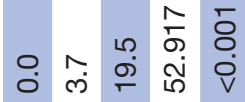

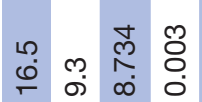

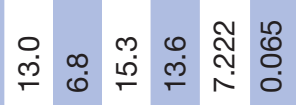

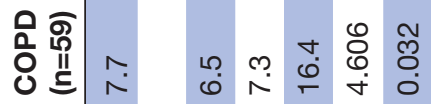

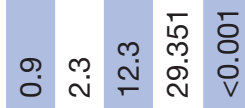

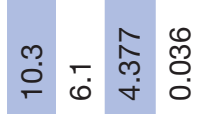

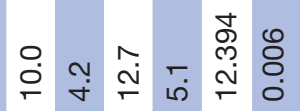

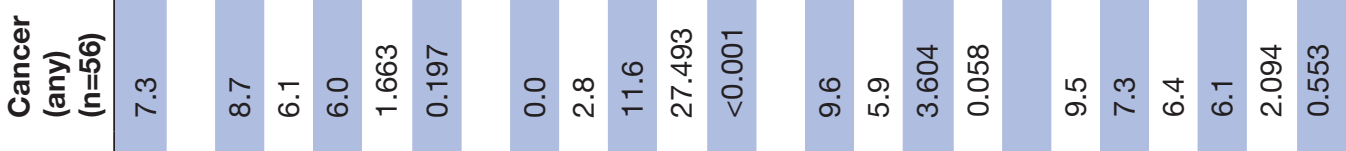

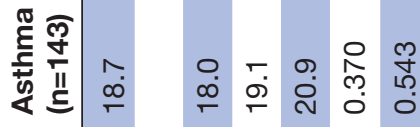

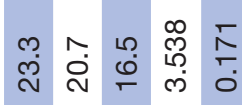

ํ.

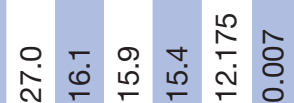

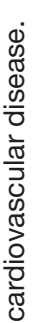

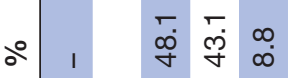

กั

co

ஸै

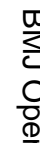

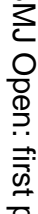

$\frac{\text { 을 }}{\frac{0}{0}}$

i

$\overrightarrow{0}$

$\dot{\vec{\omega}}$

홍.

$3_{1}^{1}$

임

心్ర

N

ํํำ

产

$z$ है 仓્ल

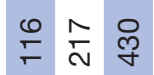

হ ํำ

ㅇํำ ำ ำ

z

ले ले

崩

य)

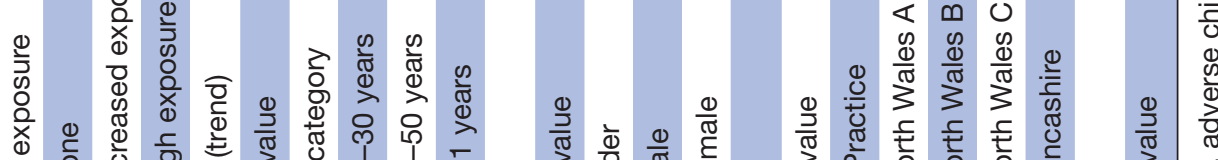

咨

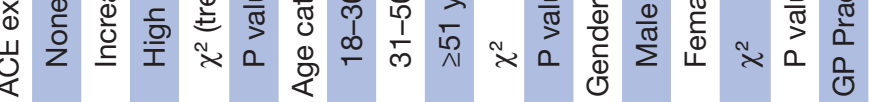

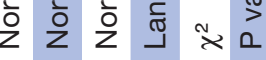


Table 2 Associations between ACEs, demographic variables and measures of service utilisation derived from patient electronic health records

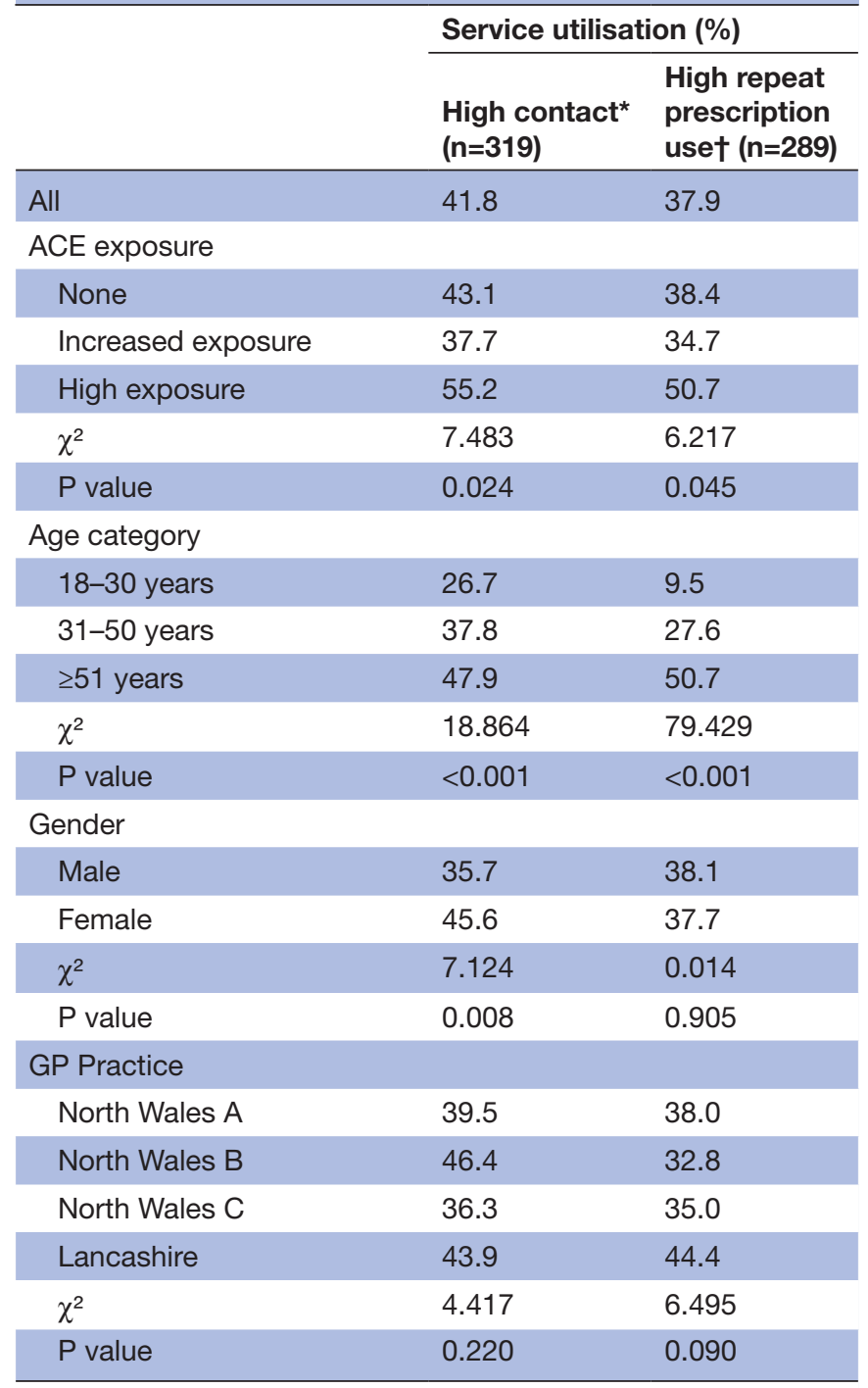

${ }^{*}$ Total number of face-to-face and telephone consultations in the past 6 months $>$ practice mean.

†Total number of items on current repeat prescription $>$ practice mean.

ACE, adverse childhood experience.;

in this sample were over one and half times more likely to experience mental health issues than men and the prevalence of mental ill health differed significantly by practice location (table 3 ). When controlling for sociodemographic variables (age, gender, location), compared with patients with no ACEs, patients with increased ACE exposure were over one and a half times more likely to experience mental health problems. Patients with high exposure were four times more likely to have a current mental health diagnosis (when compared with those with no ACE exposure; table 3).

\section{ACEs and lifestyle factors}

Exposure to adversity in childhood was significantly positively associated with obesity and current smoking in bivariate analyses (table 1). While findings did not demonstrate an independent effect of ACE exposure on obesity when controlling for socio-demographics, multivariate analysis revealed a significant independent effect of ACEs on smoking (table 3). Patients with increased ACE exposure were over one and a half times more likely to report current smoking when compared with those with no ACEs. Further, highly ACE-exposed patients were three and a half times more likely to report current smoking (when compared with those with no ACEs; table 3).

\section{ACEs and chronic health}

In bivariate analyses, a significant positive relationship was found between ACE exposure and diagnosed COPD (table 1). ACE exposure was not significantly associated with prevalence of any other chronic physical health condition examined in the sampled population, although diagnoses of asthma, CVD and multi-morbidity were all highest among those with the highest category of ACE exposure (high exposure; table 1). When analyses were stratified by age, prevalence of diagnosed COPD, CVD and hypertension significantly increased with ACE exposure in patients aged 31-50 years (online supplemental table 2). Multivariate analyses controlling for sociodemographic confounders revealed a significant independent relationship between ACEs and COPD. With high ACE exposure, patients were over four times more likely to be diagnosed with COPD (when compared with those with no exposure; table 3 ).

\section{ACEs and health service use}

EHR data on service utilisation revealed a significant relationship between ACE exposure and both high service contact and high medication use (table 2). In both cases, no ACE exposure and increased ACE exposure showed similar but substantively lower levels of service utilisation compared with high exposure. Both service use variables increased significantly with age. For contact, a significant difference by gender was also found, with female patients having more overall contact with health practitioners than their male counterparts (table 2). In multivariate analyses, a significant independent effect of history of ACEs on service use was identified for patients with high ACE exposure (figure 1). These patients were over two times as likely to have a high number of medications on repeat prescription, and 1.8 times more likely to have high contact with the practice, when compared with those patients who had not experienced ACEs (online supplemental table 3). However, analyses revealed no significant relationship between ACEs and health service use variables for those with increased ACE exposure. Modelled proportions of patients with high service contact ranged from $32 \%$ of those with increased ACE exposure to $48 \%$ of those with high ACE exposure (adjusted for age, gender and location; figure 1). 
Table 3 Logistic regression analysis of ACEs, demographics and their association with smoking, COPD and mental health

\begin{tabular}{|c|c|c|c|c|c|c|}
\hline & \multicolumn{2}{|c|}{ Current smoker } & \multicolumn{2}{|c|}{ COPD } & \multicolumn{2}{|c|}{ Mental health (any) } \\
\hline & AOR (95\% Cl) & P value & AOR (95\% CI) & $P$ value & AOR (95\% Cl) & $P$ value \\
\hline \multicolumn{7}{|l|}{ ACE exposure } \\
\hline Increased exposure & $1.76(1.15-2.69)$ & 0.009 & $1.19(0.66-2.28)$ & 0.597 & $1.58(1.11-2.25)$ & 0.012 \\
\hline High exposure & $3.52(1.91-6.49)$ & $<0.001$ & 4.17 (1.77-9.79) & 0.001 & $4.18(2.37-7.37)$ & $<0.001$ \\
\hline $31-50$ & $0.88(0.52-1.53)$ & 0.669 & $2.87(0.33-25.12)$ & 0.344 & $1.37(0.84-2.26)$ & 0.212 \\
\hline$\geq 51$ & $0.43(0.25-0.72)$ & 0.001 & $16.94(2.30-124.97)$ & 0.006 & $0.92(0.57-1.46)$ & 0.710 \\
\hline \multicolumn{7}{|l|}{ Gender* } \\
\hline Female & $0.74(0.50-1.11)$ & 0.149 & $0.74(0.43-1.30)$ & 0.299 & $1.60(1.13-2.26)$ & 0.008 \\
\hline North Wales C & $1.50(0.87-2.60)$ & 0.143 & $1.37(0.66-2.84)$ & 0.392 & $0.53(0.33-0.85)$ & 0.008 \\
\hline Lancashire & $0.82(0.48-1.41)$ & 0.466 & $0.44(0.20-1.00)$ & 0.049 & $0.37(0.24-0.58)$ & $<0.001$ \\
\hline
\end{tabular}

*Reference category for bivariate variable is male.

ACE, adverse childhood experience; AOR, adjusted odds ratio; ; $\mathrm{Cl}$, confidence interval; COPD, chronic obstructive pulmonary disease.

\section{DISCUSSION}

This paper considers the relationship between early adversity and later health and health service utilisation using data from primary care records. Findings strongly support the primacy of the dose-response relationship between ACEs and mental health. This is consistent with existing evidence from both the UK and elsewhere, which draws largely on respondents' self-reported health outcomes. ${ }^{142}$ Among general practice patients, a history of ACE exposure significantly increased the likelihood of being diagnosed with a mental health issue, with the odds of current mental ill health increasing fourfold for patients with high ACE exposure. The effect of ACE exposure on mental health was particularly pronounced for younger adults, with three-quarters of those aged 18-30 years with current mental health problems having experienced at least one ACE, and just over one in five having a history of high ACE exposure. Global burden of disease estimates suggest that mental illness now accounts for onethird of years lived with disability worldwide,${ }^{43}$ exceeding

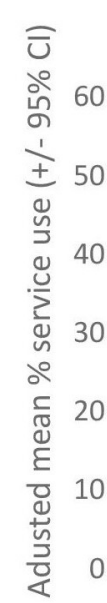

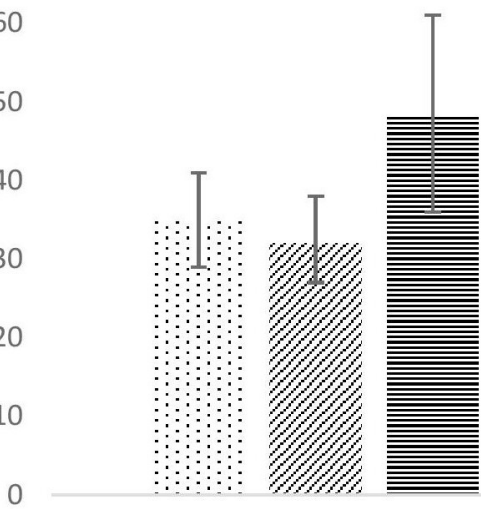

High contact*

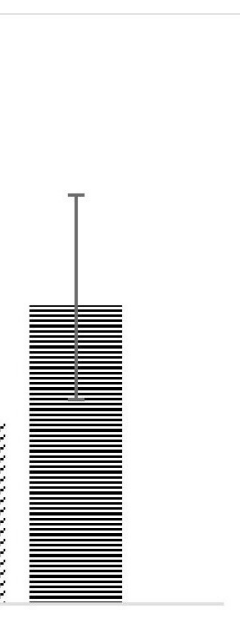

High repeat prescription use**

$\therefore$ No ACE exposure $\quad \not /$ Increased ACE exposure $\quad \equiv$ High ACE exposure

Figure 1 High health service utilisation, shown by level of ACE exposure. ACE, adverse childhood experience. *Total number of face-to-face and telephone consultations in the past 6 months > practice mean. ${ }^{*}$ Total number of items on current repeat prescription $>$ practice mean. 
the burden of cardiovascular and circulatory diseases. A recognition of the impact of early adversity on mental health has the potential to help primary care practitioners to ensure that patients receive the most appropriate diagnosis and support. In particular, understanding ACEs in younger adults may offer an opportunity for earlier intervention with those who may then be diverted from more complex mental health issues or prescribing needs in later adulthood. More holistic approaches to patient care that recognise the wider impacts of early adversity and resilience may also support the overall improvement of the patient experience in general practice.

The independent relationship between ACEs and smoking in this general practice sample is also reflective of findings from general population studies, which suggest that health-harming behaviours may reflect wider patterns of risk-proneness among ACE-exposed individuals. ${ }^{44}$ Understanding how early life experiences and current mental health may influence smoking and negative lifestyle factors may support primary care clinicians in providing more effective brief intervention and smoking cessation support. Although overall rates of tobacco use are declining in the $\mathrm{UK}^{45}$ smoking continues to be a leading preventable cause of death and a primary risk factor for many non-communicable diseases, including COPD. $^{46}$

In this study, patients with high ACE exposure were four times more likely to be diagnosed with COPD. However, no such relationships were identified between ACEs and diagnosis of other chronic health conditions (cancer, CVD, hypertension), despite such conditions being associated with ACEs elsewhere. ${ }^{14}$ It is possible that this sample may fail to capture those with chronic conditions who are receiving treatment and support through secondary or tertiary care. Hypertension and CVD did show increases in prevalence with ACE exposure in those aged 31-50 years and this may reflect ACEs leading to a relatively earlier age of onset for such conditions, a factor consistent with findings elsewhere ${ }^{19}$ In older age groups there may be some narrowing of differences by ACE exposure. However, findings at older ages may also be impacted by survival bias, as those with the greatest burden of comorbid ACEs and non-communicable diseases may have already died. Among a comparative subsection of this sample of adult general practice patients (ie, those aged $18-70$ years; $n=605$ ), while the overall prevalence of experiencing any ACE was similar to that reported in national surveys in England and Wales, ${ }^{47}$ marginally fewer respondents in this current study reported high ACE exposure. Thus, $8.8 \%$ compared with one in ten patients in the general population had been exposed to a higher number of ACEs in childhood. While this may allude to the willingness of general practice patients to openly disclose either all or certain adversities, it may also support the suggestion that adults with ACEs may be less willing to engage with health services for certain types of care (eg, routine check-ups, early care for developing symptoms) and may therefore be under-represented in this cross-sectional general practice patient sample. The reasons for and frequency by which patients with ACEs and chronic health conditions present to general practice is highlighted here as an area for further study.

Nevertheless, conditions such as hypertension and CVD that are typically associated with older age were found to occur among patients aged 31-50 years with high ACE exposure. For example, almost a quarter of patients aged 31-50 years who were diagnosed with CVD reported high ACE exposure. Being able to identify patients with a history of childhood adversity, and/or creating a culture in which patients understand the importance of this information and feel more able to disclose to a health practitioner, may support practices in intervening early with those most at risk of chronic health problems such as COPD. By supporting patients in understanding the links between their early life experiences and health behaviours and lifestyle choices, GPs may help to delay the onset of chronic illness or alleviate the severity of certain symptoms. Having a holistic understanding of a patient's needs and the social determinants of their health, including but not limited to experiences of ACEs and other childhood traumas, may also support practitioners in understanding and addressing barriers to healthcare, supporting adherence to treatment for those patients that subsequently require long-term and complex care.

Crucially, contrary to previous population studies, ${ }^{22} 23$ the relationships between ACEs and increased measures of health service utilisation (ie, attendance and medication use) were apparent at high but not increased ACE exposure. Level of actual or perceived healthcare need among those with high ACE exposure may be such that they perceive little choice but to seek support. Those with increased ACEs are a patient group of particular concern as they have an increased risk of mental or physical health problems (table 2), but potentially limited engagement with general practice (figure 1). Determining a patient's history of trauma may help practitioners to identify those with moderate risk who may benefit from more targeted trauma-informed approaches to supporting trust and improving the potential therapeutic relationship between the patient and practitioner. ${ }^{48}$

Findings presented here should be interpreted in light of the following limitations. First, analysed EHR data, even when combined across practices, had a relatively small sample size. This increases the likelihood of type II errors (ie, the number of patients with high ACE exposure and any given health outcome of interest may be too small to produce an effect that reaches statistical significance, potentially resulting in a false negative). Second, compared with diagnosed conditions that are identified by a clinician, the voluntary provision of ACE information may introduce a source of bias based on patients' willingness to report ACEs to a health professional and have such information retained within their health record. As in previous national surveys of ACEs, the retrospective nature of self-reporting also introduces the potential of recall bias, particularly for experiences 
that may have been repressed. As practices led the ACE information collection, it was not possible to analyse how differences in this may have impacted results, thus this is highlighted as an important area for further study. Third, the limited timescale over which data were available only allowed consideration of service use over a short time frame (ie, 6 months). High service utilisation can be transient, and therefore evidence suggests patterns of use are most reliably considered over a longer time frame of a year or more. ${ }^{49}$ Thus, findings from data extracted over a 6-month period cannot be extrapolated over longer periods and may be impacted by seasonal and other confounding effects. Although our findings relate to only 6 months follow-up once ACEs have been identified and recorded by GPs, those with or without ACEs can be followed up over much longer periods and this is an important development for future work. EHR data do not distinguish between contacts requested by the patient and appointments that were invited or required by the practice (eg, medication reviews, screening). Extraneous factors such as staff capacity or appointment availability may have also influenced patients' frequency of contact with the practices. Finally, the samples analysed here are not intended to be representative of broader populations but only intended to represent individuals selected from designated general practices. How representative they are of patients in other settings and how repeatable relationships identified here are in other general practices requires further studies.

\section{CONCLUSIONS}

As early life experiences continue to shape the health needs and perceptions of adults and their lifestyle choices, this research begins to describe the complex ways in which ACEs may influence when, how and for what reasons patients engage with primary healthcare, with considerable implications for their ongoing health and well-being. Findings suggest that achieving an understanding of a patient's early life history may be instrumental in supporting health practitioners in this setting to provide the most appropriate care and support, particularly for those with mental health issues, among whom ACE exposure is more pervasive. Thus, recognising the direct and indirect impact of ACEs and other life experiences on unequal distributions of risk to health and well-being has the potential to help address some of the current challenges facing general practice.

\section{Twitter Katie Hardcastle @Hardcastle_KA and Mark A Bellis @markabellis}

Acknowledgements Sincere thanks are extended to the practice managers and their administrative staff for their support in data extraction. The authors would also like to thank Gabriela Ramos Rodriguez and Jade Platts for assisting with data handling.

Contributors $\mathrm{KHa}$ and $\mathrm{MAB}$ conceived and designed the study. Data were analysed by $\mathrm{KHa}$ and $\mathrm{CAS}$. All authors ( $\mathrm{KHa}, \mathrm{MAB}, \mathrm{CAS}$ and $\mathrm{KHu}$ ) were involved in the interpretation of data and producing and editing the manuscript.

Funding The authors have not declared a specific grant for this research from any funding agency in the public, commercial or not-for-profit sectors.
Competing interests None declared.

Patient consent for publication Not required.

Ethics approval Approval and ethical advice for anonymous use of practice data was requested from the Research Governance committee in Public Health Wales and the study protocol was also scrutinised by the local Research and Development committees responsible for the general practice areas. All committees agreed to this secondary use of data for the purposes of the study.

Provenance and peer review Not commissioned; externally peer reviewed.

Data availability statement No data are available. De-identified patient data were provided by practices for the purposes of this analysis and the authors did not receive permission to share.

Open access This is an open access article distributed in accordance with the Creative Commons Attribution Non Commercial (CC BY-NC 4.0) license, which permits others to distribute, remix, adapt, build upon this work non-commercially, and license their derivative works on different terms, provided the original work is properly cited, appropriate credit is given, any changes made indicated, and the use is non-commercial. See: http://creativecommons.org/licenses/by-nc/4.0/.

ORCID iD

Katie Hardcastle http://orcid.org/0000-0003-3429-5030

\section{REFERENCES}

1 Deloitte. Global health care outlook: shaping the future. London: Deloitte, 2019.

2 Román P, Ruiz-Cantero A. La pluripatología, un fenómeno emergente y un reto para los sistemas sanitarios [Polypathology, an emerging phenonmenon and a challenge for health care systems]. Revista Clínica Española 2017;217:229-37.

3 Simó J, Gérvas J. Gasto santario en atención primaria en España: insuficiente para ofrecer servicios atrayentes para pacientes y profesionales [Health expenditure on primary care in Spain: not enough to provide attractive services to patients and health professionals SESPAS Report 2012]. Gac Sanit 2012;26:36-40.

4 Baird B, Charles A, Honeyman M, et al. Understanding pressures in general practice. London: The Kings Fund, 2016.

5 Hobbs FDR, Bankhead C, Mukhtar T, et al. Clinical workload in UK primary care: a retrospective analysis of 100 million consultations in England, 2007-14. Lancet 2016;387:2323-30.

6 Welsh Government. A healthier Wales: our plan for health and social care. Cardiff: Welsh Government, 2018.

7 England NHS. General practice forward view. London: NHS England, 2016.

8 Ipsos Mori. GP patient survey headline findings, 2019. Available: http://gp-patient.co.uk/downloads/2019/GPPS_2019_National_ infographic_PUBLIC.pdf [Accessed 21 Nov 2019].

9 Royal College of General Practitioners. 90 per cent of people with mental health problems cared for within primary care, 2017. Available: https://www.rcgp.org.uk/clinical-and-research/about/ clinical-news/2017/december/90-per-cent-of-people-with-mentalhealth-problems-cared-for-within-primary-care.aspx [Accessed 21 Nov 2019].

10 Mind. 40 per cent of all GP appointments about mental health, 2018. Available: https://www.mind.org.uk/news-campaigns/news/40-percent-of-all-gp-appointments-about-mental-health/ [Accessed 21 Nov 2019].

11 Mental Health Taskforce. The five year forward view for mental health. Leeds: NHS England, 2016.

12 Lanier P, Maguire-Jack K, Lombardi B, et al. Adverse childhood experiences and child health outcomes: comparing cumulative risk and latent class approaches. Matern Child Health J 2018;22:288-97.

13 Oh DL, Jerman P, Silvério Marques S, et al. Systematic review of pediatric health outcomes associated with childhood adversity. BMC Pediatr 2018;18:83-101.

14 Hughes K, Bellis MA, Hardcastle KA, et al. The effect of multiple adverse childhood experiences on health: a systematic review and meta-analysis. Lancet Public Health 2017;2:e356-66.

15 Berens AE, Jensen SKG, Nelson CA. Biological embedding of childhood adversity: from physiological mechanisms to clinical implications. BMC Med 2017;15:135-46.

16 Teicher MH, Samson JA, Anderson CM, et al. The effects of childhood maltreatment on brain structure, function and connectivity. Nat Rev Neurosci 2016;17:652-66.

17 Sonu S, Post S, Feinglass J. Adverse childhood experiences and the onset of chronic disease in young adulthood. Prev Med 2019;123:163-70. 
18 Koball AM, Rasmussen C, Olson-Dorff D, et al. The relationship between adverse childhood experiences, healthcare utilization, cost of care and medical comorbidities. Child Abuse Negl 2019;90:120-6.

19 Kelly-Irving M, Lepage B, Dedieu D, et al. Adverse childhood experiences and premature all-cause mortality. Eur J Epidemiol 2013;28:721-34.

20 Liu RT. Childhood adversities and depression in adulthood: current findings and future directions. Clin Psychol 2017;24:140-53.

21 Merrick MT, Ports KA, Ford DC, et al. Unpacking the impact of adverse childhood experiences on adult mental health. Child Abuse Negl 2017;69:10-19.

22 Bellis M, Hughes K, Hardcastle K, et al. The impact of adverse childhood experiences on health service use across the life course using a retrospective cohort study. J Health Serv Res Policy 2017;22:168-77.

23 Chartier MJ, Walker JR, Naimark B. Separate and cumulative effects of adverse childhood experiences in predicting adult health and health care utilization. Child Abuse Negl 2010;34:454-64.

24 Fiddler M, Jackson J, Kapur N, et al. Childhood adversity and frequent medical consultations. Gen Hosp Psychiatry 2004;26:367-77

25 Mostoufi SM, Strachan E, Chopko L, et al. Adverse childhood experiences, health perception, and the role of shared familial factors in adult twins. Child Abuse Negl 2013;37:910-6.

26 Alcalá HE, Mitchell E, Keim-Malpass J. Adverse childhood experiences and cervical cancer screening. J Womens Health 2017;26:58-63.

27 Alcalá HE, Valdez-Dadia A, von Ehrenstein OS. Adverse childhood experiences and access and utilization of health care. $J$ Public Health 2018;40:684-92.

28 Korhonen MJ, Halonen JI, Brookhart MA, et al. Childhood adversity as a predictor of non-adherence to statin therapy in adulthood. PLoS One 2015;10:e01276378.

29 Munoz RT, Hanks H, Brahm NC, et al. Adverse childhood experiences and trust in the medical profession among young adults. $J$ Health Care Poor Underserved 2019;30:238-48.

30 Dube SR. Continuing conversations about adverse childhood experiences (ACEs) screening: a public health perspective. Child Abuse Negl 2018;85:180-4.

31 Green BL, Kaltman S, Frank L, et al. Primary care providers' experiences with trauma patients: a qualitative study. Psycho Trauma 2011;3:37-41.

32 Stokes Y, Jacob J-D, Gifford W, et al. Exploring nurses' knowledge and experiences related to Trauma-Informed care. Glob Qual Nurs Res 2017:4:233339361773451.

33 Szilagyi M, Kerker BD, Storfer-Isser A, et al. Factors associated with whether pediatricians Inquire about parents' adverse childhood experiences. Acad Pediatr 2016;16:668-75.

34 Hardcastle K, Bellis MA. Asking about adverse childhood experiences (ACEs) in general practice: evaluation findings from a pilot study in Anglesey. North Wales, Cardiff: Public Health Wales, 2019.
35 Ford K, Hughes K, Hardcastle K, et al. The evidence base for routine enquiry into adverse childhood experiences: a scoping review. Child Abuse Negl 2019;91:131-46.

36 Jones CM, Merrick MT, Houry DE. Identifying and preventing adverse childhood experiences: implications for clinical practice. JAMA 2019. doi:10.1001/jama.2019.18499. [Epub ahead of print: 05 Nov 2019].

37 Centers for Disease Control and Prevention. Behavioural risk facto surveillance system ACE data. Available: http://www. cdc.gov/ violenceprevention/acestudy/ace_brfss.html [Accessed 04 Nov 2019].

38 Crouch E, Radcliff E, Nelson J, et al. The experience of adverse childhood experiences and dental care in childhood. Community Dent Oral Epidemiol 2018;46:442-8.

39 Benson T. The history of the read codes: the inaugural James read memorial lecture 2011. Inform Prim Care 2011;19:173-82.

40 Jensen PB, Jensen LJ, Brunak S. Mining electronic health records: towards better research applications and clinical care. Nat Rev Genet 2012;13:395-405.

41 IBM Knowledge Centre. SPSS statistics 24.0.0 generalized linear models. Available: https://www.ibm.com/support/knowledgecenter/ zh/SSLVMB_24.0.0/spss/advanced/idh_idd_genlin_typeofmodel.html [Accessed 26 Apr 2020].

42 Mersky JP, Topitzes J, Reynolds AJ. Impacts of adverse childhood experiences on health, mental health, and substance use in early adulthood: a cohort study of an urban, minority sample in the U.S. Child Abuse Negl 2013;37:917-25.

43 Vigo D, Thornicroft G, Atun R. Estimating the true global burden of mental illness. Lancet Psychiatry 2016;3:171-8.

44 Williamson AE, Ellis DA, Wilson $\mathrm{P}$, et al. Understanding repeated nonattendance in health services: a pilot analysis of administrative data and full study protocol for a national retrospective cohort. BMJ Open 2017;7:e014120.

45 Office for National Statistics. Adult smoking habits in the UK: 2018, 2019. Available: https://www.ons.gov.uk/peoplepopulation andcommunity/healthandsocialcare/healthandlifeexpectancies/ bulletins/adultsmokinghabitsingreatbritain/2018 [Accessed 21 Nov 2019].

46 Forey BA, Thornton AJ, Lee PN. Systematic review with metaanalysis of the epidemiological evidence relating smoking to COPD, chronic bronchitis and emphysema. BMC Pulm Med 2011;11:36-97.

47 Bellis MA, Hughes K, Ford K, et al. Adverse childhood experiences and sources of childhood resilience: a retrospective study of their combined relationships with child health and educational attendance. BMC Public Health 2018;18:792-804.

48 Sweeney A, Filson B, Kennedy A, et al. A paradigm shift: relationships in trauma-informed mental health services. BJPsych Adv 2018;24:319-33.

49 Smits FT, Brouwer HJ, van Weert HCP, et al. Predictability of persistent frequent attendance: a historic 3-year cohort study. $\mathrm{Br} J$ Gen Pract 2009;59:e44-50. 